\title{
BRECHAS DE GÉNERO EN LA EDUCACIÓN SUPERIOR EN CHILE Y SU IMPACTO EN LA SEGREGACIÓN LABORAL. UNA REVISIÓN SISTEMÁTICA DE LA LITERATURA
}

\author{
GENDER GAPS IN HIGHER EDUCATION IN CHILE AND THEIR IMPACT ON \\ LABOR SEGREGATION. A SYSTEMATIC REVIEW
}

\author{
DANIELA GUZMÁN SANHUEZA*1 \\ *Universidad De Atacama (ChIle) Y Universidad De Salamanca (España)
}

\section{RESUMEN}

Desde una revisión sistemática de la literatura en bases de datos WoS, Scopus y Scielo y utilizando el modelo PRISMA, se obtienen 25 artículos que abordan la relación entre el género y la segregación laboral en los últimos 5 años en Chile. La segregación laboral horizontal comienza a gestarse con la elección de la carrera profesional a estudiar, cuyo impacto se observa posteriormente en la vida laboral las elecciones de las carreras, especialidades, ámbitos de desempeño e incluso metodologías de aprendizaje se relacionan al género. La presencia de estereotipos y los modelos de división sexual del trabajo operan como catalizadores de las restricciones intrínsecas (creencias interiorizadas) y restricciones extrínsecas (derivadas de normativa y procedimientos existentes 0 ausencia de estos en la educación superior), que desincentivan la participación de las mujeres en carreras que históricamente han sido desarrolladas por hombres. En relación a las opciones en Educación Superior, las mujeres se concentran en los ámbitos de salud, educación y servicios sociales, mientras los hombres se desarrollan en las matemáticas, carreras ligadas a la ciencias y tecnología, que son mejor remuneradas (Servicio de Información de Educación Superior, SIES, 2021). En Chile, ingresan a la educación superior más mujeres que hombres, en todos los tipos de instituciones. Sin embargo, existen áreas del conocimiento en donde la brecha de género negativa se hace más notoria. Según las cifras que maneja la Subsecretaría de Educación Superior del país, la brecha de género en Ciencias Básicas es de -0,1\% y en Tecnología es de $-65,7 \%$.

Palabras clave: Revisión sistemática, Igualdad de oportunidades, Segregación laboral, Segregación en Educación Superior, Discriminación por sexo.

\begin{abstract}
From a systematic review of the existing literature in databases such as WoS, Scopus and Scielo and by making use of the PRISMA model, 25 articles on the relationship between gender and occupational segregation in the last 5 years in Chile have been analyzed. Horizontal occupational segregation begins at the very moment in which women choose their degree since it will have a repercussion in their future for it affects their future decisions, their future working life, their fields of expertise and even there are learning methodologies linked to gender. The presence of stereotypes and role models affecting the occupational breakdown by gender are catalysts of the intrinsic constraints (internalized beliefs) and extrinsic constraints (those linked to the norms and existing procedures, or the absence of them in higher education), since they discourage the irruption of women in fields which have been traditionally associated to men. With regards to higher education, women tend to enroll in the fields of health, education and social services whilst men focus on STEM fields. It is important to highlight that in Chile there are more women who enroll in the university regardless of the nature of the institution. However, there are fields of knowledge in which the gender gap is sharp. According to the data gathered by the Subsecretaría de Educación Superior of Chile, the gender gap in basic sciences is $-0.1 \%$ whilst it reaches a $65.7 \%$ in Technology.
\end{abstract}

Keywords: Systematized review, Equal opportunities, Labor segregation, Segregation in Higher Education, Discrimination by sex.

\footnotetext{
${ }_{1}^{1}$ Autor de correspondencia: Daniela Guzmán Sanhueza. Daniela.guzman@uda.cl
} 


\section{Introducción}

La segregación ocupacional es una de las manifestaciones de la desigualdad de género que, desde hace un tiempo, ha dejado de naturalizarse y comienza a tener la preocupación y ocupación de los países en esta materia. Desde los organismos internacionales se entiende que la segregación ocupacional es una consecuencia más de la desigualdad de las mujeres en el mercado laboral.

La urgencia de abordarla radica en la necesidad de minimizar las brechas de género en lo laboral que produce un acceso limitado y desigual a los recursos (económicos, materiales, de protección social) y con ello, costos sociales y económicos (Aldaz y Eguía, 2016). Las cifras indican que las mujeres acceden a ciertos trabajos, principalmente feminizados, y que por lo tanto están infravalorados respecto a los trabajos considerados tradicionalmente masculinos. Desde la lógica de la división sexual del trabajo, las mujeres realizan trabajos menos valorados social y económicamente (Freedman, 2004) y además acceden a una menor diversidad de campos laborales (Maira, 2017).

La segregación ocupacional, también referida en la literatura como segregación laboral, es en sí misma una situación discriminatoria y funciona como catalizador de una serie de brechas posteriores que se funden en la precariedad laboral de la mujer, tales como la brecha salarial (Melkas y Anker, 1997), salud ocupacional, brecha en la participación laboral, brecha en el uso de tecnologías (Jiménez y Fernández, 2016), entre otros.

Dentro de la segregación ocupacional encontramos dos tipos, la vertical y la horizontal. La primera se relaciona con la dificultad por razón de género de ascender y ocupar cargos de poder en la trayectoria laboral, y la segunda, objeto de esta investigación, se denomina segregación horizontal y refiere a la dificultad en la ocupación de áreas laborales por razón de género. Ambos representan fuentes de discriminación y en ambas juegan un papel importante los estereotipos.

Existe un compromiso del Estado de Chile en hacer efectiva la Declaración sobre la igualdad de oportunidades y de trato para las trabajadoras (OIT, 1975), la cual es ratificada de manera interna por Decreto, incorporándose en la legislación nacional. En ella se reconoce que las mujeres deben gozar del mismo trato y optar a las mismas oportunidades que los hombres y que es intolerable cualquier forma de discriminación, enfatizando que los estados partes deben adoptar todas las medidas necesarias para asegurar la no discriminación por género y el logro efectivo de la igualdad entre mujeres y hombres, abordando, por ejemplo la segregación horizontal y vertical cuando establece la necesidad de "fomentar su distribución más equilibrada y justa (del empleo) en los distintos sectores de la economía, en los diversos ramos y ocupaciones y en los distintos niveles de calificación y responsabilidad" (art. 16, inciso 1).

Existen distintas perspectivas que pretenden dar una explicación a la segregación ocupacional por género, pero son las teorías no económicas o feministas las que explican la división de ocupaciones por sexo utilizando factores ajenos al mercado laboral, entendiendo que los comportamientos económicos son la expresión de elementos sociales y culturales (derivados del carácter subordinado del género femenino), y no la explicación de los mismos (Nicolás, López y Cortés, 2008).

La segregación ocupacional termina siendo la expresión de una línea de segregación y discriminación que va desde la trayectoria educativa y socialización temprana. Cuando la Real Academia Española define discriminación, establece que es "seleccionar excluyendo", lo que implica desestimar la participación de un género en favor del otro (Marín, 2017) y aunque, se ha avanzado en la inserción laboral de las mujeres (presenta una proporción del 45\% aproximadamente), "su participación está atravesada por condiciones de desigualdad que dificultan su acceso, permanencia y movilidad" (Buquet, 2016, p. 28). La directa relación entre la segregación académica en la educación superior y la segregación laboral posterior se visualiza en los obstáculos que se presentan y que se perciben como parte de la trayectoria de las mujeres. La elección de la carrera profesional que se ingresa a estudiar se pudiese estimar que es una decisión 
personal. Sin embargo, esta decisión está condicionada por todo un proceso de socialización y por una organización estructural del trabajo y la formación que, desde un insuficiente e insipiente abordaje de los estereotipos de género, reproducen desigualdades (Martin, 2008).

Es de interés del presente estudio la revisión del estado actual del conocimiento respecto a la segregación laboral horizontal en Chile, la relación de ésta con la segregación académica en estudios superiores y la elección de la carrera profesional, todos estos elementos analizados como fenómenos de discriminación que perjudican a la mujer y precariza su situación en el mundo del trabajo remunerado.

\section{Objetivos e hipótesis}

Este estudio busca evidenciar la estrecha relación entre las características de la formación superior y la permanencia de la segregación en el desarrollo laboral de las mujeres. En este sentido, la hipótesis inicial es que existe una relación estrecha entre segregación en la formación y segregación laboral de las mujeres que presenta características que las acompañan durante toda su trayectoria laboral y que precarizan su situación. Para ello se propone "Reconocer el estado del conocimiento científico en la temática en Chile, registrado en bases de datos Scopus, Wos (ESCl) y Scielo, desde el año 2016 al 2021".

\section{Metodología}

\subsection{Diseño}

La revisión sistemática es un estudio de tipo descriptivo, cuya utilidad es reunir un número determinado de investigaciones (cuantitativas o cualitativas) y resumir sus resultados. Denominada por Grant y Booth (2009) como revisión sistemática cualitativa, sintetiza la evidencia integrando o comparando hallazgos. Es un tipo de investigación secundaria, es decir, que utiliza datos ya recopilados por otras investigaciones y que han sido publicados, con el propósito de reconocer el avance del conocimiento en una materia específica. Sigue una estructura y se organiza en base a criterios predefinidos de selección/exclusión de artículos, tales como: dimensión temporal, dimensión espacial y el objeto de estudio (delimitados en conceptos 0 términos para orientar la búsqueda). En este sentido, la investigación incorpora artículos científicos publicados en revistas de acceso abierto desde el año 2016 al 2021, utilizando los buscadores Scopus, Scielo y ESCI (WoS), reconocidos como aquellos que condensan la mayor variedad de publicaciones en Ciencias Sociales. La tabla 1, presenta los criterios del protocolo de investigación que representan los filtros de búsqueda:

Tabla 1.

Resumen protocolo de investigación

\begin{tabular}{|c|c|}
\hline ÍTEM & DESCRIPCIÓN \\
\hline Tema de interés & Brechas de género y segregación laboral. \\
\hline $\begin{array}{l}\text { Descriptores } 0 \text { palabras } \\
\text { claves }\end{array}$ & $\begin{array}{l}\text { Género, Segregación ocupacional, discriminación laboral, Trabajo y } \\
\text { Educación Superior. }\end{array}$ \\
\hline Dimensión temporal & Últimos 5 años (2016 a 2021). \\
\hline Dimensión espacial & Chile \\
\hline Criterios de selección & Artículos científicos de acceso abierto. \\
\hline $\begin{array}{ll}\text { Descripción } & \text { del } \\
\text { procedimiento } & \end{array}$ & $\begin{array}{l}\text { Se definen } 3 \text { bases de datos: Scielo, Scopus, ESCI Se ingresan las } \\
\text { palabras claves de forma independiente y luego asociadas por los }\end{array}$ \\
\hline $\begin{array}{l}\text { metodológico para } \\
\text { búsqueda artículos. }\end{array}$ & términos boleanos AND Y OR. Se eliminan repeticiones de los artículos. \\
\hline
\end{tabular}




\subsection{Unidades de análisis participantes}

Una vez aplicado el procedimiento predefinido en el protocolo de la revisión sistemática, y utilizando el modelo PRISMA (Liberati et al, 2009), se obtiene un total de 25 artículos científicos que cumplen con los criterios de inclusión, correspondiendo a las unidades de análisis de la investigación. En primera instancia se realizó una revisión de la literatura en las bases de datos Scielo, Web Of Science (ESCI) y Scopus. En la búsqueda se utilizaron las palabras claves en inglés, Gender, Occupational Segregation, Labor Discrimination, Work and Higher Education con el conector booleano AND y OR. Se limitó al periodo entre los años 2016 y 2021, utilizando como filtro de búsqueda inicial las palabras claves (keywords) de las investigaciones. Finalmente se utilizaron como criterios de inclusión tipos de estudios cuantitativos y cualitativos, de acceso abierto, se estableció como criterio lingüístico investigaciones en inglés, portugués y español y como criterio geográfico estudios realizados en Chile. La gestión de referencias se realizó con el software Mendeley utilizado para la revisión y eliminación de duplicados. Todo este proceder se presenta de manera esquemática en la figura 1:

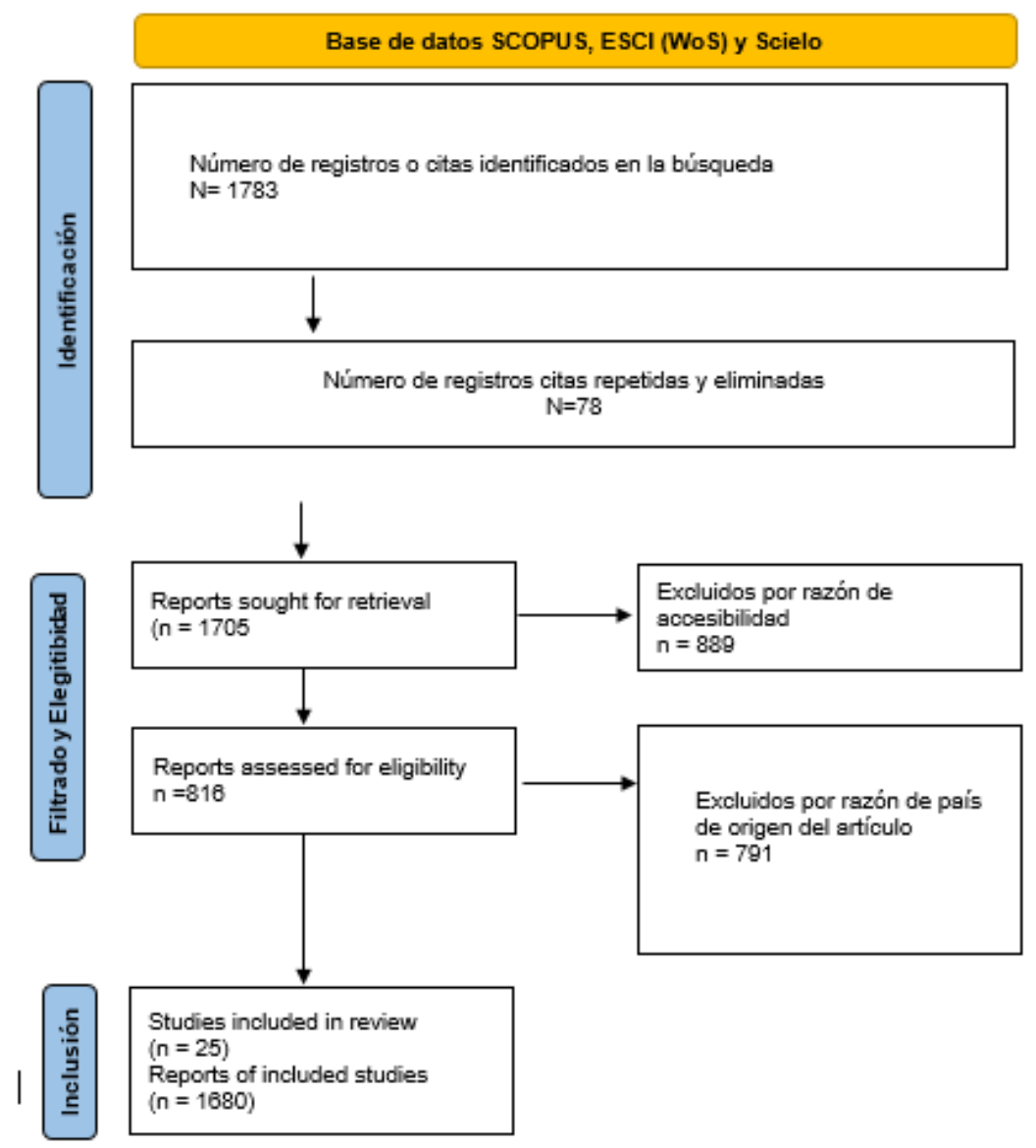

Figura 1. Flujograma de búsqueda de artículos científicos

\subsection{Procedimiento y análisis de datos}

Los artículos fueron organizados temáticamente, a través de la identificación de los énfasis descriptivos que presentaban. Se realiza un análisis de contenido semántico inicial (Álvarez, 2013; Ballester, 2006; Duque, 2014), lo que deriva en la identificación de 2 dimensiones. Luego cada dimensión es organizada en categorías, tal como se presenta a continuación en la tabla 2: 
Tabla 2.

Dimensiones y categorías

\begin{tabular}{|c|c|c|c|c|}
\hline \multirow[t]{2}{*}{ Dimensión } & \multirow[t]{2}{*}{ Categoría } & \multicolumn{3}{|c|}{ Número de artículos } \\
\hline & & $\mathrm{ESCl}$ & Scopus & Scielo \\
\hline \multirow{3}{*}{$\begin{array}{l}\text { Segregación en la } \\
\text { formación } \\
\text { (13 artículos) }\end{array}$} & Trayectorias educativas diferenciadas & 4 & 0 & 4 \\
\hline & $\begin{array}{l}\text { Feminización y masculinización de carreras } \\
\text { profesionales y técnicas }\end{array}$ & 1 & 0 & 2 \\
\hline & Participación de la mujer en carreras STEM. & 1 & 0 & 2 \\
\hline $\begin{array}{l}\text { Segregación } \\
\text { laboral }\end{array}$ & $\begin{array}{l}\text { Precarización de la trayectoria laboral de las } \\
\text { mujeres }\end{array}$ & 5 & 1 & 1 \\
\hline (12 artículos) & Brecha Salarial & 1 & 0 & 3 \\
\hline
\end{tabular}

La revisión de artículos científicos permite evidenciar el estado del conocimiento en la materia y refleja el interés por quienes realizan investigación. Los resultados han sido organizados en dos dimensiones derivadas del análisis de los artículos encontrados, formación y desempeño laboral. Dentro de formación se identifican las siguientes categorías: Trayectorias educativas diferenciadas, en donde se encuentran elementos como la deserción, progresión y desempeño académico diferenciado por género; feminización y masculinización de carreras profesionales y técnicas, que indica la relación con los estereotipos de género de la participación diferencial en ciertas áreas del conocimiento y la participación de la mujer en carreras STEM. En el ámbito de desempeño laboral se encuentran precarización de la trayectoria laboral de las mujeres, en donde se especifican las diversas y constantes barreras que las mujeres deben sortear y la concreción de la desigualdad en la afectación del bienestar psicológico de la mujer por sobre la del hombre; la persistencia de la Brecha Salarial; $y$ la incorporación de las TIC's y el teletrabajo.

\section{Resultados}

\subsection{Segregación en la formación}

\subsubsection{Trayectorias educativas diferenciadas}

La trayectoria educativa corresponde al recorrido que realizan las personas en el proceso de educación formal (UNICEF, 2020). En Chile, se inicia desde el nivel preescolar, pasando por primaria, secundaria y educación superior. Existe una trayectoria teórica, que en Chile está determinada por 13 años de escolaridad obligatoria y por un currículo oficial que define temas, contenidos y metodologías según nivel y una trayectoria real, que no siempre coincide con la trayectoria teórica, y es ahí cuando se producen discontinuidades y disrupciones (Recart et al, 2020).

Los estudios indican que no existe diferencia significativa entre la capacidad de un niño o una niña para aprender en las distintas áreas del conocimiento. Sino más bien, la brecha se marca a medida que avanza en edad, lo que hace presumir que esta mayor habilidad en una u otra área es el resultado del proceso de socialización (Aragón y Navarro, 2016).

La definición de los contenidos en la trayectoria teórica escolar no es neutra y su delimitación ha aportado a la diferenciación de trayectorias educativas por género. Así encontramos en el pasado reciente textos oficiales que, a través de lecturas y actividades, han contribuido a fomentar estereotipos y discriminaciones. A medida que se ha aumentado el conocimiento y la conciencia de las desigualdades de género, se ha avanzado en considerar la necesidad de neutralizar estos elementos, generando remediales que permitan a los establecimientos educativos avanzar en igualdad, concretadas en iniciativas específicas y que carecen de formalidad. Así lo demuestra un estudio cualitativo, realizado en un establecimiento de educación media tipo en Santiago de Chile, indica que parte importante de la comunidad educativa (estudiantes y docentes) evidencia escasez 
de estrategias formales para abordar la temática al interior del establecimiento (Baeza y Lamadrid, 2018).

Luego del egreso de la educación secundaria, último eslabón obligatorio de los 13 años de escolaridad comprometido por ley, viene la elección en la continuidad de estudios superiores. Esta elección, lejos de ser natural, está condicionada a las lógicas de mercado, en donde, producto de la reproducción de desigualdades, se evidencian barreras que el estudiantado proyecta como obstáculos en la consecución de sus estudios superiores (Sepúlveda, 2017; Sevilla et al., 2019). Por ejemplo, en las carreras mineras, tanto técnicas como profesionales la proyección laboral y empleabilidad son bien evaluadas, y representan elementos que se consideran en la elección de formación profesional, sin embargo, existe preocupación por la hegemonía masculina del rubro e incertidumbre por compatibilizar la maternidad (Baena et al, 2020).

Respecto a la educación superior, Chile presenta indicadores aún más complejos. Según la tasa de cobertura neta, las mujeres corresponden al $43,9 \%$ de las matriculadas y los hombres al $37,0 \%$, lo cual muestra una brecha de género positiva de $6,9 \%$, la más alta de la que se tenga registro. Es decir, ingresan a la educación superior más mujeres que hombres, en todos los tipos de instituciones como Centro de Formación Técnica, Universidades e Institutos profesionales. Sin embargo, el informe presenta que existen áreas en donde la brecha de género negativa se hace evidencia. En Ciencias Básica la brecha es de $-0,1 \%$ y en Tecnología es de $-65,7 \%$ (SIES, 2021).

Un estudio realizado en la educación superior técnica, indica que existen tres modalidades marcadas en el funcionamiento del sistema: una que se concentra en la formación profesional y autonomía de las mujeres; otra en función de la disciplina reproduce los roles de género tradicionales; y, una tercera y actual modalidad que implica la incorporación de la perspectiva de género en la formación, pero que está mediada por las lógicas de mercado laboral, es decir, sucumbe a las desigualdades del medio. (Sepúlveda 2017). Otra investigación, realizada en una carrera altamente masculinizada, muestra que, aun cuando desde la formalidad se establezca la perspectiva de género, las alumnas no son capaces de contrarrestar el machismo de sus profesores o de sus compañeros de estudios (Salinas y Romaní, 2020).

Respecto a la diferencia de género en los porcentajes de deserción en Educación Superior, las investigaciones reportan mayor deserción de mujeres en las carreras masculinizadas. Una investigación realizada en la Escuela de Informática y Telecomunicaciones de un instituto profesional de la región de Valparaíso en Chile, indica que el $100 \%$ de sus deserciones corresponden a mujeres y explica este fenómeno al componente de integración social, en una instancia en donde la participación de mujeres es marginal. Mencionan que los factores que tienen mayor incidencia en la deserción son el género, año de egreso de enseñanza media y jornada de estudio (González y Arismendi, 2018). De manera complementaria un estudio cuyo objetivo fue identificar rasgos de personalidad en estudiantes de ciencias de la computación y determinar si están relacionados con el desempeño académico, obtiene que existe una relación entre el rendimiento académico y los rasgos de personalidad medidos por la escala de motivación educativa, el ranking de ingreso a la universidad y género. Se determina así que los hombres tienen mayor rendimiento académico que las mujeres, y esto podría estar relacionado con factores psicológicos como la baja autoestima y la falta de estímulo durante su educación secundaria (De la Fuente et al, 2020).

La tabla 3 muestra los resultados de las trayectorias educativas. 
Tabla 3.

Trayectorias educativas diferenciadas. Fuente: Elaboración propia, 2021

\begin{tabular}{|c|c|c|}
\hline Categoría & Artículos & Resultados \\
\hline \multirow[t]{8}{*}{$\begin{array}{l}\text { Trayectorias } \\
\text { educativas } \\
\text { diferenciadas }\end{array}$} & $\begin{array}{l}\text { Análisis y predicción del comportamiento de los } \\
\text { estudiantes de ingeniería y su relación con el } \\
\text { rendimiento académico mediante el análisis de } \\
\text { datos }\end{array}$ & $\begin{array}{l}\text { Relación entre el rendimiento académicos, los } \\
\text { rasgos de personalidad, el ranking de ingreso a } \\
\text { la universidad y el género (De la Fuente et al, } \\
\text { 2020). }\end{array}$ \\
\hline & $\begin{array}{l}\text { Deserción estudiantil en la educación superior } \\
\text { técnico profesional: explorando factores que } \\
\text { inciden a alumnos de primer año. }\end{array}$ & $\begin{array}{l}\text { Los resultados muestran que los factores con } \\
\text { mayor significancia estadística, asociados a la } \\
\text { deserción estudiantil, corresponden al género, } \\
\text { año de egreso de enseñanza media y jornada de } \\
\text { estudio (González y Arismendi, 2018). }\end{array}$ \\
\hline & $\begin{array}{l}\text { Estudiantes mujeres en educación técnica } \\
\text { profesional en Chile: continuidad y ruptura en } \\
\text { inclusión educativa }\end{array}$ & $\begin{array}{l}\text { Caracterización de tres modalidades de } \\
\text { formación en la educación técnica profesional } \\
\text { que impactan de manera diferente a las mujeres } \\
\text { (Sepúlveda, 2019). }\end{array}$ \\
\hline & $\begin{array}{l}\text { Trayectorias educativas según género. } \\
\text { Lo invisible para la política educativa chilena. }\end{array}$ & $\begin{array}{l}\text { Se constata una postura acrítica a la segregación } \\
\text { en las elecciones vocacionales de las y los } \\
\text { jóvenes y una escasez de estrategias formales al } \\
\text { interior de la escuela para abordarla (Baeza, } \\
2018 \text { ). }\end{array}$ \\
\hline & $\begin{array}{l}\text { Consideraciones sobre empleabilidad en } \\
\text { educación superior. }\end{array}$ & $\begin{array}{l}\text { "Se concluye que empleabilidad, en este } \\
\text { contexto, tiende a presentarse como una } \\
\text { instrumentalización de la rendición de cuentas } \\
\text { respecto de los procesos de enseñanza- } \\
\text { aprendizaje" (Orellana, p.273). }\end{array}$ \\
\hline & $\begin{array}{l}\text { El uso de una actividad de aprendizaje } \\
\text { cooperativo con estudiantes universitarios: una } \\
\text { experiencia de género }\end{array}$ & $\begin{array}{l}\text { Las mujeres valoraron mejor la relación del } \\
\text { aprendizaje cooperativo con los roles docentes } \\
\text { futuros. Además, las alumnas prefieren que los } \\
\text { grupos se organicen según criterios académicos } \\
\text { y que se mantengan estables durante todo el } \\
\text { período académico (Baena, 2020). }\end{array}$ \\
\hline & $\begin{array}{l}\text { Percepciones de los graduados sobre las } \\
\text { competencias y la preparación para la } \\
\text { transición al mercado laboral: el efecto del } \\
\text { género y la experiencia laboral durante la } \\
\text { educación superior }\end{array}$ & $\begin{array}{l}\text { En la preparación para la transición al mercado } \\
\text { laboral, existen diferencias de género en la } \\
\text { percepción del desarrollo de competencias y } \\
\text { efecto de la experiencia laboral (Monteiro, 2016). }\end{array}$ \\
\hline & $\begin{array}{l}\text { La perspectiva de género en la formación inicial } \\
\text { docente en la Educación Física } \\
\text { chilena }\end{array}$ & $\begin{array}{l}\text { En Chile existe una infrarrepresentación } \\
\text { femenina en los estudios de pedagogía en } \\
\text { educación física lo que contribuye a la } \\
\text { reproducción de los estereotipos de género } \\
\text { (Matus, 2020). }\end{array}$ \\
\hline
\end{tabular}

\subsubsection{Feminización y masculinización de carreras profesionales y técnicas}

La división sexual del trabajo ha generado una segmentación artificial de las áreas del conocimiento. Desde un modelo hegemónico, las carreras profesionales fueron proyectando aspectos asociados al género, manteniendo perfiles profesionales según los requerimientos del mercado laboral.

Desde la noción instrumentalizada de empleabilidad (Orellana, 2018), se construye una asociación entre formación e inserción laboral que no es ajena al género, pues existe una demanda diferencial de fuerza de trabajo de los distintos sectores económicos (Maubrigades, 2020). Se configuran profesiones que tradicionalmente son ejercidas por mujeres y profesiones que tradicionalmente son ejercidas por hombres, lo que se denomina feminización y masculinización de las carreras profesionales, respectivamente y que condiciona la proyección de la misma. Un 
estudio realizado con estudiantes de la carrera de minería en Chile indica que las jóvenes perciben inequidad desde el inicio hasta el término de su formación profesional manifestando preocupación por los obstáculos laborales que enfrentarán (Salinas y Romaní, 2017).

Las ocupaciones feminizadas son mucho menos numerosas que las masculinizadas, por lo que las mujeres cuentan con menor espacio de elección que los hombres en el mercado del trabajo (Maira, 2017), lo que ya implica una merma en la inserción laboral y elección profesional femenina.

Un estudio realizado en estudiantes de medicina de 11 países de Latinoamérica indica que existe una asociación entre el género femenino y la intención de elegir Obstetricia / Ginecología, Pediatría, Cirugía Pediátrica, Dermatología y Oncología. El número de estudiantes mujeres matriculadas en carreras de medicina a nivel Latinoamericano ha aumentado notoriamente, y de los once países analizados (entre ellos Chile), solo tres tenían una mayor proporción de estudiantes varones, lo que indica el fenómeno de la feminización de la carrera de medicina. Es decir, no solo implica el ingreso de más mujeres que hombres a la formación de una carrera profesional, sino también el egreso satisfactorio de la misma ( $\mathrm{Ng}$-Sueng et al, 2016).

Desde el 2016 al 2020 se observa que el porcentaje de ingresos de mujeres a la educación superior es mayor que el de los hombres, tanto en universidades como en centros de formación técnica. En Chile, las carreras con mayor ingreso femenino corresponden a las áreas de salud y educación con brechas positivas superiores a 50 puntos. Esto implica que el ingreso en estas carreras es mayoritariamente femenino (dos veces más mujeres que hombres), lo que hace que sea considerada una carrera feminizada. Además, se observa una brecha positiva en promedios de puntajes de ingreso. Si bien la tasa de aprobación en carreras de pregrado de las mujeres es mayor al de los hombres (88,1\% versus $81,7 \%$ ), existen carreras (llamadas masculinizadas) en donde la presencia de mujeres disminuye considerablemente, aun cuando su ingreso ha estado marcado por estas brechas positivas (SIES, 2021).

La tabla 4 muestra los resultados de la feminización y masculinización de carreras profesionales y técnicas.

Tabla 4.

Feminización y masculinización de carreras profesionales y técnicas. Fuente: Elaboración propia, 2021

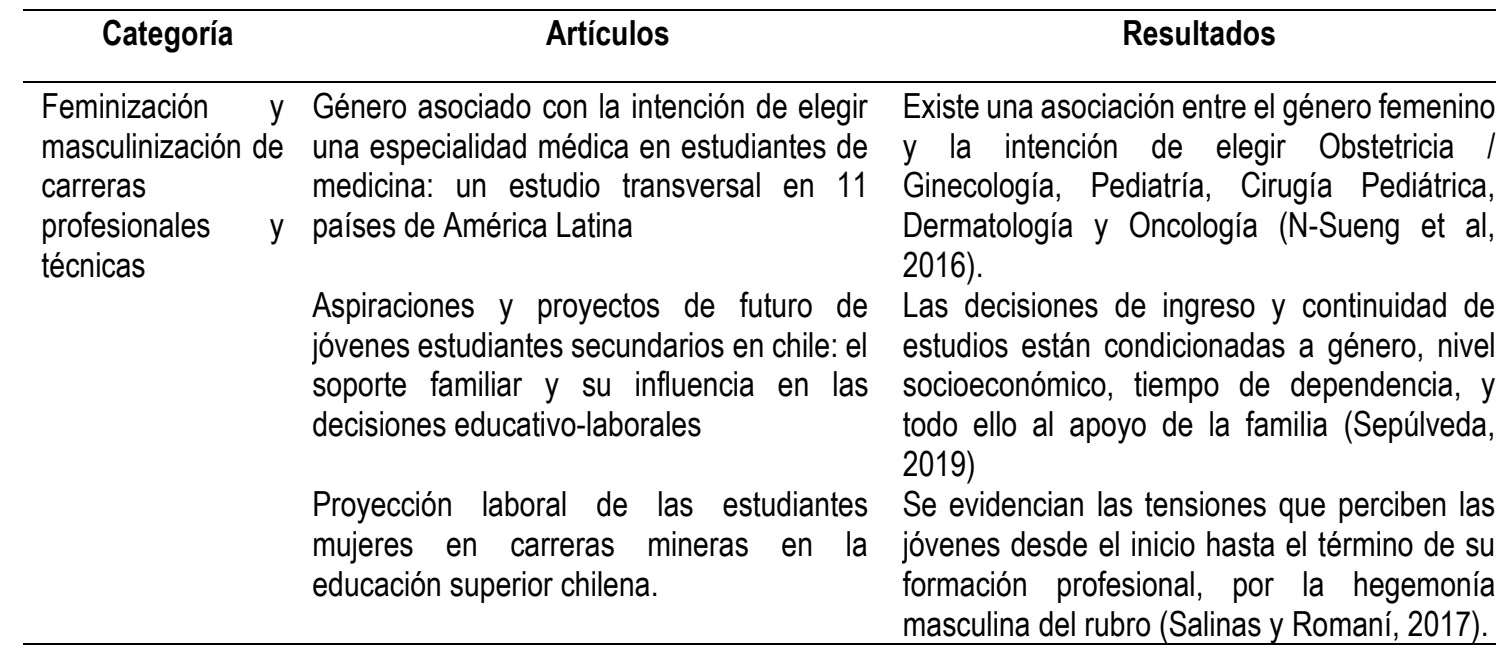

\subsubsection{Participación de la mujer en carreras STEM}

La segregación horizontal comienza a gestarse con la elección de la carrera profesional a estudiar, cuyo impacto se observa posteriormente en la vida laboral. La presencia de estereotipos y los modelos de división sexual del trabajo operan como catalizadores de las restricciones 
intrínsecas (creencias interiorizadas) y restricciones extrínsecas (derivadas de normativa y procedimientos existentes 0 ausencia de estos en la educación superior) que desincentivan la participación de las mujeres en carreras que históricamente han sido desarrolladas por hombres. En relación a las opciones en Educación Superior, las mujeres se concentran en los ámbitos de salud, educación y servicios sociales mientras los hombres se desarrollan en las matemáticas, carreras ligadas a la ciencias y tecnología, que son mejor remuneradas (Servicio de Información de Educación Superior, SIES, 2021).

Coherente a lo anteriormente planteado, la Unesco menciona que:

En la educación superior, los hombres son mayoría en las matrículas de carreras relacionadas con ingeniería, manufactura, construcción, tecnologías y ciencias de la comunicación; en cambio las mujeres son mayoría en carreras como educación, artes, salud, bienestar, ciencias sociales, periodismo, negocios y leyes (UNESCO, 2019. P. 20).

En esa misma línea, un estudio de Comunidad Mujer realizado el 2017, revela que la diferencia de porcentaje de egreso en carreras "masculinizadas" y carreras "feminizadas" (Comunidad Mujer, 2019). El 2020, el Movimiento STEM (movimiento que promueve la participación de mujeres en ciencias, tecnología, ingeniería y matemáticas) junto al centro de investigación de alta dirección pública, realizan un estudio para conocer la participación de las mujeres en la elección de carreras STEM (sigla en inglés que refiere a carreras de Ciencias, Tecnología, Ingeniería y Matemáticas). Los resultados indican que las mujeres son influenciadas en su decisión por sus familias un $3 \%$ más que los hombres y que la matricula en carreras STEM es muy inferior a la de los hombres. Cerca de un $30 \%$ de las mujeres que ingresan a la Universidad, lo hace a estas carreras.

La relevancia de avanzar en la incorporación de mujeres a las disciplinas STEM y procurar su desarrollo radica en el avenimiento de lo que algunos llaman la cuarta revolución industrial, que impacta no solo a la industria (y con ello, a las relaciones laborales) sino la economía y la sociedad. Con la incorporación de la tecnología, el mundo del trabajo va sufriendo transformaciones que modifican la relación de las personas con el trabajo. Ya en la plataforma de Beijing (1995), la ausencia de las mujeres en las Ciencias, Tecnologías, Ingenierías y Matemáticas era una preocupación y focaliza su interés en abordarla, reconociendo la existencia de obstáculos en los planes de estudio. Se generaron iniciativas para abordar esta brecha como el programa SAGA, realizado por la UNESCO entre el año 2015 y 2018 (Garduño, 2021).

Existe preocupación de la institucionalidad internacional de abordar con urgencia la brecha en la participación de las mujeres en carreras STEM. Se debe incorporar acciones que aborden la brecha de ingreso, pero también la brecha que se va agudizando a medida que se avanza en la trayectoria académica y laboral. Por ejemplo, según la UNESCO, a nivel mundial, el $43 \%$ de las mujeres en profesiones STEM abandona su carrera, de tiempo completo, una vez que tienen 0 adoptan a su primer hijo, en contraste con el $23 \%$ de los hombres o que la brecha de género llega a 40 puntos porcentuales de diferencia entre hombres y mujeres dedicados a la investigación en estas áreas (UNESCO, 2019).

Los avances tecnológicos han llevado al mundo del trabajo a transformar configuración inicial. La digitalización de las tareas, la relativización de los tiempos, la disposición de espacios virtuales para el trabajo y la especificación del mismo hacia la obtención de metas o productos, han configurado un nuevo concepto. Lamentablemente las cifras indican que a nivel latino americano "sólo $0.5 \%$ de las niñas consideran trabajar como profesionales de las TIC en un futuro, contra $3.9 \%$ de los niños; esta razón se mantiene a lo largo de la trayectoria estudiantil" (Marchionni, Gasparini, y Edo, 2018). En el informe de educación superior en el año 2021, se indica que el área de tecnología es el que reporta menor participación de mujeres, con una brecha de género negativa de inserción de -65 puntos (SIES, 2021). Es importante considerar que existen factores individuales que funcionan como barreras en la segregación horizontal, tales como la 
autopercepción, la eficacia personal y el interés pero que están condicionados por los estereotipos de género, incorporados a través del proceso de socialización de niños y niñas (Aragón, 2016).

La tabla 5 muestra los resultados de la participación de la mujer en carreras STEM.

Tabla 5.

Participación de la mujer en carreras STEM. Fuente: Elaboración propia, 2021

\begin{tabular}{|c|c|c|}
\hline Categoría & Artículos & Resultados \\
\hline $\begin{array}{ll}\text { Participación } & \text { de } \\
\text { mujeres } & \text { en } \\
\text { carreras STEM }\end{array}$ & $\begin{array}{l}\text { Exploraciones de diferencias de género en } \\
\text { los predictores de dominio general y } \\
\text { específicos de las habilidades matemáticas } \\
\text { tempranas. } \\
\text { Construir puentes en la educación superior: } \\
\text { Una ruta entre la formación profesional y la } \\
\text { industria minera del } 2035 \text {. } \\
\text { El empleo de las mujeres en el nuevo } \\
\text { espacio tecnológico. }\end{array}$ & $\begin{array}{l}\text { Las disposiciones son condicionadas a } \\
\text { estereotipos, no existiendo evidencia de } \\
\text { diferencia de rendimientos en matemática entre } \\
\text { niños y niñas (Aragón, 2016). } \\
\text { Las alumnas no son capaces de contrarrestar el } \\
\text { machismo de sus profesores o de sus } \\
\text { compañeros de estudios (Salinas y Romaní, } \\
\text { 2020) } \\
\text { Establece que mientras persistan las diferentes } \\
\text { brechas estructurales de género, la digitalización } \\
\text { ampliará la desigualdad de género, al agregar } \\
\text { una nueva brecha, la digital y tecnológica } \\
\text { (Baamonde, 2019). }\end{array}$ \\
\hline
\end{tabular}

\subsection{Segregación laboral}

Al analizar los artículos que focalizan su interés investigativo en la segregación laboral, se diferencias tres categorías de análisis que son: Precarización de la trayectoria laboral (tabla 6), Brecha Salarial (tabla 7) y TiCs y teletrabajo.

El acceso de las mujeres al mundo laboral remunerado también está caracterizado por su participación diferenciada en distintas áreas de trabajo. La existencia de trabajos dominados por hombres, en donde la participación de mujeres trabajadoras es menor y en algunos casos, mínima es producto de la segregación horizontal. Los sectores económicos y ocupacionales que concentran más mujeres se clasifican como feminizadas, donde lo hacen los hombres, como masculinizadas y donde existe una participación más equitativa de mujeres y hombres, se conocen como mixtas (Gómez, Huesca y Horbath, 2017). Por ejemplo, en Chile las mujeres representan el $92 \%$ de quienes se desempeñan en el Servicio Doméstico, el $70 \%$ de quienes trabajan en Enseñanza y el $75 \%$ de quienes están ocupados en Servicios Sociales y de Salud (Inostroza y Ceccarelli, 2018). Por el contrario, en sectores primarios, están sobrerepresentadas (Comunidad Mujer, 2019).

Existen diferencias en la inserción laboral de hombres y mujeres. Aun cuando las mujeres han ingresado a la esfera del trabajo remunerado de forma masiva, Chile presenta una de las tasas más bajas de América Latina. Hoy nos encontramos con una proporción mujer/hombre de 45,3 a 68,5 aproximadamente, lo que representa una brecha de un -23,2 (INE, 2021), las condiciones y trayectorias que ambos géneros desarrollan se configuran de manera diferente. Se identifican barreras culturales que provienen de la división sexual del trabajo y reproducidas constantemente por mecanismos institucionales y de mercado, que derivan en acentuadas condiciones de precariedad, inestabilidad e informalidad laboral (Espino y Sauval, 2016). Un estudio comparativo del índice de segregación laboral de Chile e Italia, dos contextos socioeconómicos distintos, indica que el índice de segregación es similar en ambos países, a pesar de las diferencias significativas en los contextos socioeconómicos e institucionales (Semenza, Boccardo y Sarti, 2021).

Otra investigación realizada con egresados y egresadas de la carrera de Ingeniería de Universidad de Chile analiza las diferencias en el desarrollo de la carrera profesional por sexo a través de la segregación horizontal y vertical. Utilizando una muestra de 439 egresados, concluye 
que existe segregación horizontal en las industrias masculinizadas y mixtas, que la probabilidad de pertenecer a un sector varía en forma diferencial para egresadas y egresados según algunas variables socioeconómicas y organizacionales y que existe devaluación del trabajo de la mujer por industria y áreas funcionales (Sáez, 2019). Coincidentemente, y un área de trabajo distinta, las profesionales de la medicina que estaban realizando su especialidad en Chile indican que perciben mayor discriminación negativa en el ejercicio profesional (Chuang, et al., 2019).

Tabla 6.

Precariedad de las trayectorias laborales de las mujeres. Fuente: Elaboración propia, 2021

\begin{tabular}{|c|c|c|}
\hline Categoría & Artículos & Resultados \\
\hline \multirow[t]{7}{*}{$\begin{array}{l}\text { Precarizaci } \\
\text { ón de la } \\
\text { trayectoria } \\
\text { laboral de } \\
\text { las mujeres }\end{array}$} & $\begin{array}{l}\text { ¿Frenos al empoderamiento económico? } \\
\text { Factores que limitan la inserción laboral y la } \\
\text { calidad del empleo de las mujeres: el caso } \\
\text { chileno. }\end{array}$ & $\begin{array}{l}\text { Identificación de barreras culturales en la inserción } \\
\text { laboral femenina tanto intrínsecas como impuestas } \\
\text { (Espino y Sauval, 2016). }\end{array}$ \\
\hline & $\begin{array}{l}\text { Trayectorias laborales de las mujeres y } \\
\text { violencia en el lugar de trabajo: una cuestión } \\
\text { de género. }\end{array}$ & $\begin{array}{l}\text { Se identifican tres tipos de violencia hacia las } \\
\text { mujeres chilenas durante su trayectoria laboral: } \\
\text { trato condescendiente, discriminación contra la } \\
\text { maternidad y acosos sexua (Undurraga y } \\
\text { Hornickel, 2020). }\end{array}$ \\
\hline & $\begin{array}{l}\text { Asociaciones entre distrés, riesgos } \\
\text { psicosociales y calidad del empleo en } \\
\text { trabajadores/as asalariados/as en Chile: una } \\
\text { perspectiva de género. }\end{array}$ & $\begin{array}{l}\text { Las mujeres presentan mayores riesgos } \\
\text { psicosociales y de distrés que los hombres. Incide } \\
\text { el doble rol, la calidad del empleo, estabilidad, } \\
\text { violencia simbólica (Ansoleaga, Díaz y Mauro, } \\
\text { 2016). }\end{array}$ \\
\hline & $\begin{array}{l}\text { Bienestar psicológico en mujeres que } \\
\text { desempeñan profesiones tradicionalmente } \\
\text { masculinas. }\end{array}$ & $\begin{array}{l}\text { Las mujeres presentan mayores riesgos } \\
\text { psicosociales que los hombres, siendo ellas } \\
\text { quienes más enferman. Sin embargo, los hombres } \\
\text { son quienes tienen mayores accidentes laborales } \\
\text { (Bahamondes et al, 2017). }\end{array}$ \\
\hline & $\begin{array}{l}\text { So Far, ¿so similar? Labor market feminization } \\
\text { in Italy and Chile. }\end{array}$ & $\begin{array}{l}\text { Nivel de segregación laboral similar entre estos } \\
\text { países aun cuando son contextos económicos, } \\
\text { políticos y sociales distintos (Semenza, 2021). }\end{array}$ \\
\hline & $\begin{array}{l}\text { Género y envejecimiento en el trabajo en } \\
\text { Chile: empleo, condiciones laborales, } \\
\text { conciliación y salud de hombres y mujeres en } \\
\text { una fuerza laboral que envejece. }\end{array}$ & $\begin{array}{l}\text { Quienes trabajan hasta la vejez en Chile enfrentan } \\
\text { trabajos precarios con protección limitada y varias } \\
\text { condiciones laborales adversas. Las mujeres } \\
\text { llevan la doble carga del trabajo remunerado y no } \\
\text { remunerado en sus últimos años (Vives et al, } \\
2018 \text { ). }\end{array}$ \\
\hline & ¿lgualdad de género en otorrinolaringología? & $\begin{array}{l}\text { Mayor discriminación negativa hacia mujeres en el } \\
\text { ejercicio profesional, cuestionando sus habilidades } \\
\text { quirúrgicas y realizando comentarios sexistas } \\
\text { (Chuang et al, 2019). }\end{array}$ \\
\hline
\end{tabular}

Uno de los aspectos que interfiere en la trayectoria laboral de las mujeres es la violencia en el lugar de trabajo, la cual se identifica como una barrera en las trayectorias laborales. En esta línea, un estudio que relaciona trayectorias laborales con violencia de género en el trabajo, identifica 3 tipos de violencia: el trato condescendiente, la discriminación frente a la maternidad y el acoso sexual, siendo éste último el más determinante en la interrupción o giro drástico de la trayectoria laboral femenina (Undurraga y Hornickel, 2020) la violencia, además de precarizar las condiciones de trabajo, representa una manera de perpetuar las relaciones patriarcales y la situación de subordinación de la mujer impuesta por un sistema laboral que se basa en la competencia y el individualismo. Se encuentra que la reacción de las mujeres a la violencia es de resignación y de resistencia. Esto se diferencia por la vulnerabilidad a la discriminación, dada por las diferentes 
categorías sociales que se les atribuyen y por las cuales son sometidas a múltiples discriminaciones (Espino y Sauval, 2016).

Con relación a los factores que limitan la inserción laboral e interfieren en la calidad del empleo de las mujeres, un estudio cuantitativo realizado en el año 2016 con datos de la encuesta CASEN (2011) indica que la inserción laboral de la mujer es más informal y de menor calidad que los hombres. Aplicando el modelo de probabilidad, divide las variables en restricciones intrínsecas e impuestas. En las primeras se asocia la menor inserción laboral e independencia económica con estar casadas, tener hijos o hijas pequeños (inferior a 5 años), a diferencia de los hombres en donde la relación entre variables es positiva. En la segunda se identifica el acceso a servicios de cuidado, el alcance de mayores niveles de formación y el lugar de residencia (urbano o rural), como restricciones impuestas (Espino y Sauval, 2016).

Otra arista de precarización laboral es la que se presenta a través de la brecha en salud de las mujeres. Las cifras indican que las mujeres se ausentan menos de sus puestos de trabajo por accidentabilidad laboral, sin embrago, esto no se repite al considerar enfermedades laborales. En efecto, las cifras indican, que los hombres se accidentan más que las mujeres, los hombres reportan mayor cantidad de días por reposo laboral por accidentes de trabajo ( $15 \%$ mujeres versus $22 \%$ hombres aproximadamente) y que las mujeres tienen mayor porcentaje de diagnósticos de enfermedades profesionales. La tasa de enfermedades profesionales indica que las mujeres doblan en incidencia la cantidad de enfermedades profesionales de los hombres (IST, 2019). Un estudio cuantitativo realizado a nivel nacional arroja asociación entre distrés, riesgos psicosociales, calidad del empleo y género, evidenciándose una asociación directa entre precariedad laboral y distrés en ambos géneros. Sin embargo, en todos los escenarios laborales, las mujeres presentan mayor distrés que los hombres (Ansoleaga y Díaz, 2016). Otro estudio realizado en la ciudad de Punta Arenas, indica que la existencia de percepción de discriminación de las mujeres que ocupan puestos de trabajo definidos como tradicionalmente masculinos disminuye su bienestar psicológico, aun cuando la percepción de discriminación se encuentra en un nivel intermedio. La percepción de discriminación se mide a través de una escala que aborda la presencia de actos de discriminación en la vida cotidiana de las mujeres y que son asignables a su actual actividad laboral (Bahamondes et al, 2017).

La persistencia de desigualdades en el sistema laboral en Chile genera escenarios diferenciados para hombres y mujeres, desincentivando la incorporación y permanencia femenina en el mundo laboral, lo que impacta en las trayectorias laborales y finalmente, en la jubilación, realidad que es percibida por las mujeres más jóvenes, quienes, ante la constatación de esta desigualdad del sistema de pensiones, manifiestan desconfianza de éste como principal sustento económico en la vejez, y la idea de utilizar otras estrategias previsionales, como ahorrar por cuenta propia o invertir en bienes inmuebles (Undurraga y Becker, 2019).

Como menciona Torns y Recio (2012), "la desigualdad no desaparece, sino que se transforma". (p.178) La no atención desde las políticas públicas de la desigualdad de género en lo laboral no solo disminuye las posibilidades de las propias mujeres de proyectar su autonomía económica, sino también pone en riesgo la democracia y la sustentabilidad del mercado. Según estudio realizado por Vives et al. (2018) en Chile, a medida que se envejece las condiciones laborales de los y las chilenas empeora:

Las tasas de ocupación disminuyen drásticamente después de los 54 años en mujeres y 59 en hombres. Las mujeres y los hombres mayores que continúan trabajando tienen más probabilidades de realizar trabajos por cuenta propia (autónomos) que los trabajadores más jóvenes; en el caso de las mujeres, en los hogares como trabajadoras domésticas, y los hombres, en la agricultura. La protección social y los derechos laborales se reducen notablemente en los 
trabajadores mayores. El trabajo a tiempo parcial aumenta a partir de los 50 años, especialmente entre las mujeres, pero la jornada laboral media no desciende por debajo de las 30 ha semanales ni para las mujeres ni para los hombres (p. 476).

El ascenso y movilidad laboral es más difícil para las mujeres que para los hombres. La discriminación es este sentido se expresa en la segregación ocupacional por razón de género que "es un fenómeno presente en todos los países, con independencia del nivel de desarrollo económico, e indiferente a la existencia de condicionantes religiosos, culturales y sociales particulares" (Escarrer et al, 2008. P. 4). Existe la diferenciación entre dos tipos de segregación, la horizontal y la vertical. El fenómeno del techo de cristal se explica desde la segregación vertical. Conceptualmente se define como la discriminación experimentada por las mujeres y que no les permite, u obstaculiza, su ascenso a cargos de mayor poder, responsabilidad y remuneración. Esto produce una distancia en el acceso y desarrollo de cargos de mayor jerarquía entre hombres y mujeres.

La escasa participación de las mujeres en cargos de poder y toma de decisión se expresa en el Ranking Mujeres en la Alta Dirección 2018 (Comunidad Mujer y Virtus Partner, 2018), en donde las mujeres representan un número muy por debajo de la presencia de los hombres en estos espacios, tal como se menciona:

"Todos los directorios de las empresas IPSA, correspondiente a 40 empresas con mayor presencia bursátil, están presididos por hombres y solo tienen un $6,2 \%$ de participación femenina. En el caso de los directorios de las empresas del Sistema de Empresas Públicas (SEP) se componen por un $42,1 \%$ de directoras en promedio y el $21,1 \%$ de las mesas está encabezada por una de ellas, mientras que en el grupo de las Otras Empresas Públicas hay una mujer presidenta y, en promedio, los directorios tienen una participación femenina del 15\%" (Comunidad Mujer, 2019. p. 7)

Tabla 7.

Brecha salarial. Fuente: Elaboración propia, 2021

\begin{tabular}{|c|c|c|}
\hline Categoría & Artículos & Principales resultados \\
\hline \multirow[t]{4}{*}{$\begin{array}{l}\text { Brecha } \\
\text { Salarial }\end{array}$} & $\begin{array}{l}\text { Evolución y análisis de la brecha } \\
\text { salarial por género en Chile. }\end{array}$ & $\begin{array}{l}\text { Disminución en la discriminación salarial cuando observamos el } \\
\text { periodo completo (1990-2017), la cual ocurrió principalmente entre } \\
1990 \text { y 2003, y tras ella la discriminación se ha mantenido } \\
\text { relativamente constante hasta } 2017 \text { (Salce, 2021). }\end{array}$ \\
\hline & $\begin{array}{l}\text { Mujeres trabajadoras y pensiones } \\
\text { en Chile. }\end{array}$ & $\begin{array}{l}\text { Percepción negativa del sistema de pensiones, desconfianza y } \\
\text { conciencia de diferencias por nivel socioeconómico, en contraste } \\
\text { con baja conciencia de género. Sobre las estrategias } \\
\text { previsionales, predomina la idea de ahorrar por sobre su práctica, } \\
\text { incluyendo inversiones inmobiliarias para paliar las bajas } \\
\text { pensiones (Undurraga y Becker, 2019). }\end{array}$ \\
\hline & $\begin{array}{l}\text { Mujeres en el trabajo: persistencia } \\
\text { de los condicionantes de género } \\
\text { en el ámbito laboral. }\end{array}$ & $\begin{array}{l}\text { Se analizaron las percepciones de las mujeres sobre brecha } \\
\text { salarial, constatándose que, si bien las entrevistadas se mostraron } \\
\text { familiarizadas y a favor de demandas del feminismo ello no } \\
\text { redundo en una interpelación subjetiva que posibilite una } \\
\text { apropiación de dichos reclamos ante las inequidades vivenciadas } \\
\text { y relatadas por ellas mismas en sus espacios de trabajo, en } \\
\text { comparación con sus colegas y superiores varones (Flego y } \\
\text { Ortega, 2020). }\end{array}$ \\
\hline & $\begin{array}{l}\text { Participación y segregación } \\
\text { ocupacional de género en los } \\
\text { sectores económicos de América } \\
\text { Latina durante el siglo XX }\end{array}$ & $\begin{array}{l}\text { El crecimiento de las economías en sector servicios explica el } \\
\text { aumento de inserción laboral femenina en la región. Su } \\
\text { participación se concentra en los servicios personales y sociales y } \\
\text { particularmente en el servicio doméstico. Esto repercute } \\
\text { visiblemente en las remuneraciones recibidas (Maubrigades, } \\
2020 \text { ). }\end{array}$ \\
\hline
\end{tabular}


En Chile, el porcentaje de mujeres que puede acceder a cargos de poder está dentro de los más bajos de los países que pertenecen a la OCDE. Un estudio realizado con egresados y egresadas de la Universidad de Chile reporta diferencias en la proporción de egresadas y egresados de los tres niveles jerárquicos (profesionales, gerentes y ejecutivos).

Esta brecha en la trayectoria laboral tiene su correlato en las brechas salariales. La interrupción en las trayectorias laborales, la segregación horizontal y vertical, entre otras manifestaciones de desigualdad, obstaculizan el progreso en las carreras laborales y el acceso a mejores remuneraciones. La brecha salarial representa la diferencia que existe entre la remuneración en el mercado del trabajo entre hombres y mujeres. Este indicador se ha mantenido estable en los años, a pesar de la denuncia constante y el discurso de las organizaciones internacionales de acabar con esta diferencia injusta y que provoca desigualdad. Antes se podía atribuir la diferencia salarial a la diferencia de cualificación por género, sin embargo, la educación de las mujeres muestra cifras mayores a la de los hombres, tanto en ingreso como en promoción (SIES, 2021).

La desigualdad producida por la división sexual del trabajo se concreta con la brecha salarial. Esta, que se mantiene de manera persistente, corresponde la valoración diferenciada de las actividades productivas, según quien las realice (hombres o mujeres). Lexartza et al. (2019), en el informe denominado "La brecha salarial entre hombres y mujeres en América Latina", reconocen el origen de la brecha salarial y la desvalorización económica del trabajo de las mujeres en la división sexual del trabajo, aun cuando se ha intentado argumentar esta brecha desde otras posturas teóricas como la menor productividad de las mujeres o la intermitencia en el mercado laboral.

Según ONU Mujeres, las principales causas de las brechas de género en el trabajo remunerado son: empleo a tiempo parcial, pues las mujeres presentan un mayor porcentaje, el cual se explica al contrastar con el porcentaje de mujeres que asume el trabajo no remunerado de cuidado de sus familias; peores empleos, es decir, las mujeres están presentes en empleos menor valorados productivamente, e incluso, socialmente; auto minusvaloración que tiene como consecuencia que las mujeres negocian menos su salario y aceptan con más facilidad lo que se les ofrece, pues están en un contexto de discriminación que debilita el ejercicio de sus derechos; y, por ignorancia que no visualiza las diferencias salariales por género. Existe una normalización de parte de los empleadores que se puede referir como desconocimiento que hace que no se adopten medidas, por lo que las diferencias se perpetúan. En todo el mundo se evidencia la existencia de esta brecha, con variaciones que están relacionadas al avance de los derechos de las mujeres a nivel laboral de cada país. Es facultad de poderes públicos, promover el empoderamiento de las mujeres, y asegurar la correcta valoración económica de los empleos (ONU, 2020)

América Latina y el Caribe es la tercera región que ostenta una mayor brecha en el salario entre hombres y mujeres, situación que incide de manera directa en la brecha de pobreza entre mujeres y hombres. Las cifras indican que las mujeres son más pobres y esto tiene relación, entre otros factores, con la brecha salarial, que representa el trato discriminatorio por razón de sexo, ya que por igual trabajo las mujeres perciben menor remuneración. Las mujeres ganan menos, ahorran menos y tiene mayoritariamente trabajos informales. Un informe presentado por la ONU en septiembre del año 2019, indica que el sueldo de las mujeres es un $23 \%$ inferior al de los hombres, situación que se proyecta se profundice con las consecuencias de la pandemia (ONU, 2020).

En Chile, la brecha es aún más marcada. La diferencia entre los sueldos de hombres y mujeres es de un 27\%, 5 puntos porcentuales superior al promedio de América Latina, según estos estudios. Si la brecha la analizamos desde el estadígrafo de la mediana de ingresos mensuales, ésta se estrecha, llegando al 16,5\% (INE, 2021), cifra que se acrecienta de manera notoria en espacios laborales masculinizados. Si bien se muestra una disminución en la discriminación salarial en Chile, principalmente entre 1990 y 2003, la discriminación se ha mantenido 
relativamente constante (Salce, 2021). La segregación laboral de género concentra a las mujeres en sectores de alto riesgo económico y de pérdida de empleos frente a la pandemia. Están subrepresentadas en los campos de ciencia, tecnología, ingeniería y matemáticas lo que limita sus posibilidades de una mejor inserción económica.

Por otro lado, existe una directa relación entre segregación horizontal y brecha económica. Los sectores que mayormente están ocupados por mujeres son, además, menor remunerados y mayormente desprotegidos. Por ejemplo, hasta hace muy poco tiempo en Chile no existía regulación del Servicio Doméstico, quedando este sector de la actividad laboral a disposición de las oscilaciones de la oferta y la demanda. Una de las recomendaciones que la Comisión para la equidad de género de la ONU le realiza al país en el año 2012 es profundizar en medidas que generen condiciones de igualdad para el servicio doméstico, en relación a reconocer derechos laborales e implementarlos a través de la ley, la cual es promulgada dos años (Ley $N^{0} 20.786$ ) después de recibida dicha recomendación.

En el último informe correspondiente al año 2021, la CEDAW solicita al estado de Chile referirse a:

"Las medidas adoptadas para eliminar la discriminación contra las mujeres en el empleo, lo que incluye la adopción y aplicación de medidas especiales de carácter temporal para reducir las desigualdades de género en el mercado laboral en términos de segregación horizontal y vertical, en relación con las mujeres pertenecientes a grupos desfavorecidos, incluidas las mujeres indígenas, las mujeres con discapacidad y las mujeres migrantes, en los sectores público y privado" (Comité para la Eliminación de la Discriminación contra la Mujer, 2021).

Por tanto, siguiendo a Espino y Sauval (2016) la segregación ocupacional deriva en un empobrecimiento de las mujeres al estar asociadas a una inserción laboral precaria, que frena su empoderamiento a través de barreras de inserción laboral intrínsecas e impuestas

\section{Discusión y conclusiones}

La revisión realizada examina los artículos científicos más relevantes en revistas indexadas asociadas a los buscadores WoS, Scopus y Scielo. Se evidencia que existe una variedad de conocimiento publicado que aborda de manera indirecta la segregación horizontal y que está relacionada con la formación y el ejercicio profesional, relevándose la existencia de carreras feminizadas y masculinizadas que proyectan la segregación hacia los espacios laborales. La segregación horizontal está articulada desde antes con las trayectorias educativas tempranas y la socialización de la familia que incentivan el desarrollo de ciertas competencias según género, y que se conciertan como gustos o vocación y se expresan en las elecciones profesionales.

La literatura científica es clara al plantear que son los elementos sociales y estructurales los que refuerzan esta división desigual de las áreas de conocimiento, siendo relevante la conclusión de ejercer modificaciones en dichos elementos que permitan avanzar hacia la igualdad. Así entonces, los elementos individuales, mencionados como internos, intrínsecos y visualizados a través de elecciones personales, son también externos, ya que responden a las barreras de género que se encuentran en el mercado laboral (Aldaz y Eguiz, 2016).

La incorporación de la perspectiva de género en la formación varía en las carreras de las cuales se cuenta con investigación. Por ejemplo, educación física se menciona que no existe estudios suficientes que aborden. De igual forma pasa en las carreras de minería reportadas. En el área de salud, al parecer los obstáculos se presentan en términos relacionales. Es decir, la subestimación de las habilidades de las mujeres y la constante permanencia de violencia simbólica (comentarios, invisibilización, vacíos, prejuicios, etc.) dan paso a un ambiente hostil, en donde muchas mujeres se masculinizan para sortear los estereotipos que perjudican su avance en la formación. En carrera masculinizadas, estudios nos indican que son las mujeres quienes desertan lo cual muestra que 
esta tendencia no responde a razones personales, sino que existen elementos estructurales, de la carrera, mercado laboral, organización del proceso formativo, que están interviniendo negativamente en la permanencia de las mujeres al interior de las plantas estudiantiles.

Mientras no se desborde la división sexual del trabajo, con todas las aristas que esta presenta, no será posible impactar en las brechas de género en el ámbito laboral ni en la segregación ocupacional. El cuarto plan de igualdad que Chile implementa a través del Ministerio de la Mujer y Equidad de género tiene este objetivo, buscando la "reducción de la desigualdad retributiva, reduciendo la segregación en el mercado laboral, así como mejorando el acceso de las mujeres al desarrollo productivo - industrial y la innovación tecnológica; reducir las desigualdades que afectan a las mujeres en sus iniciativas de emprendimiento y en el acceso a instrumentos de fomento productivo, y modificar los estereotipos de género que afectan las relaciones laborales y limitan las oportunidades que tienen la diversidad de mujeres en sus trayectorias laborales" (2018, p. 18).

Los cambios que se vienen experimentando en la configuración del trabajo, de la mano de la incorporación de la tecnología y la digitalización del trabajo, implica que las mujeres, que tienen una menor participación en carreras profesionales STEM, puedan acceder a los beneficios de estos cambios. Sin embargo, las TiCs y el teletrabajo se han revelado como nuevas formas de segregación ocupacional, en lugar de suponer un avance hacia la igualdad de oportunidades, tal y como se concebían en su origen.

\section{Referencias}

Aidis, R., y Weeks, J. (2016). Mapping the gendered ecosystem: The evolution of measurement tools for comparative high-impact female entrepreneur development. International Journal of Gender and Entrepreneurship, 8(4), 330-352. https://doi.org/10.1108/IJGE-12-20150044

Aldaz, L. y Eguía, B. (2016). Segregación laboral por género en España y en el País Vasco. Un análisis de cohortes. Estudios de Economía Aplicada, 34(1),133-153. https://www.redalyc .org/articulo.oa?id=30143731007

Álvarez, J. (2013). Análisis de contenido semántico: evolución del discurso modal de la inmigración en la prensa española. EMPIRIA, 25, 73-92. https://doi.org/10.5944/empiria.25.2013.3798

*Ansoleaga, E., Díaz, X., y Mauro, A. (2016). Associação entre estresse, riscos psicossociais e qualidade do emprego de trabalhadores assalariados chilenos: Uma perspectiva de gênero. Cadernos de Saude Publica, 32(7). https://doi.org/10.1590/0102-311X00176814

*Aragón Mendizábal, E., y Navarro Guzmán, J. I. (2016). Exploración de diferencias de género en los predictores de dominio general y específico de las habilidades matemáticas tempranas. Suma Psicologica, 23(2), 71-79. https://doi.org/10.1016/j.sumpsi .2016.04.001

*Baena, S., Jerez, D., Fernández, F. T., y López, J. (2020). The use of a cooperative-learning activity with university students: A gender experience. Sustainability (Switzerland), 12(21), 1-12. https://doi.org/10.3390/su12219292

*Baeza, A. y Lamadrid, S. (2018). Trayectorias educativas según género. Lo invisible para la política educativa chilena. Revista de Investigación Educativa, 36(2), 471-490. http://dx.doi.org/10.6018/rie.36.2.298061

*BAAMONDE, MEC (2019). El empleo de las mujeres en el nuevo espacio tecnológico. Tiempo de Paz, 134, 31-42. https://dialnet.unirioja.es/servlet/articulo?codigo=7426973 
*Bahamondes, M., Miranda, S., Avendaño, S., y Estrada, C. (2017). Bienestar psicológico en mujeres que desempeñan profesiones tradicionalmente masculinas TT - Psychological well-being in women performing traditionally male occupations. Revista de Psicología, 26(1), 120-132. https://www.redalyc.org/pdf/264/26452899011.pdf

Ballester, L. (2006). El análisis semántico y pragmático de las entrevistas de investigación. EMPIRIA. Revista de Metodología de Ciencias Sociales, 11, 107-129. https://doi.org/ 10.5944/empiria.11.2006.1111

Buquet, A. (2016). El orden de género en la educación superior: una aproximación interdisciplinaria. Nómadas, 44, 27-43. http://www.scielo.org.co/scielo.php?script =sci_arttext\&pid=S0121-75502016000100003\&Ing=en\&tIng=es.

Comunidad Mujer. (2019). IPG Chile, un acelerador para el cierre de las brechas económicas de género. Boletín \#45. Iniciativa de paridad de género en Chile. http://www.comunidadmujer.cl/biblioteca-publicaciones/wp-content/uploads/ 2019/02/ComunidadMujer_Boleti\%CC\%81n_45_IPG-Chile-un-acelerador-para-el-cierrede-las-brechas-econo\%CC\%81micas-de-ge\%CC\%81nero_PP.pdf

Comunidad Mujer y Virtus Partners. (2018). Ranking mujeres en la Alta Dirección 2018. Chile. https://bit.ly/2qAlbOS

*Chuang, C; Ricci, L; Aguirre, P; Pineda, D; Nicolás, N y Pereira, P. (2019). ¿lgualdad de género en otorrinoloringología? Revista de Otorrinolaringología y Cirugía de Cabeza y Cuello, 79 (4), 387-394. https://doi.org/10.36857/resu.2018.188.510

*De la Fuente, H; Guzman, C, Crawford K, Foschino G, Crawford B, Soto R, León de la Barra C, Cisternas, F, Monfroy E, Becerra, M, Elórtegui, C. Analysis and Prediction of Engineering Student Behavior and Their Relation to Academic Performance Using Data Analytics Techniques. Applied Sciences, 10(20), 7114. https://doi-org.ezproxy.usal.es/10.3390 lapp10207114

Duque, E. (2014). Análisis de contenido mediante análisis de palabras clave: La representación de los participantes en los discursos de Esperanza Aguirre. Mediaciones Sociales, 13,39-73. http://dx.doi.org/10.5209/rev_MESO.2014.n13.49432

Inostroza, D y Ceccarelli, J. (2018). Mirada conceptual y analítica a los asalariados del sector público: Encuesta Nacional de Empleo (ENE). Documento de trabajo. https://www.ine.cl/docs/default-source/documentos-de-trabajo/asalariados_publicos .pdf?sfvrsn=7befe2f3_4

Escarrer, C., Navarro, C., Bosch, E. y Ferrer, V.A. (2008). "La segregación horizontal y vertical por género entre el PAS y el PDI de la Universitat de les Illes Balears". "I Congreso Internacional sobre Género, Trabajo y Economía Informal". En Género, Trabajo y Economía Informal. Universidad Miguel Hernández. http://ve.umh.es/sieg .1/docs/lCongresolnternacional/comunicaciones/sciv06.pdf

*Espino, A., y Sauval, M. (2016). ¿Frenos al empoderamiento económico? Factores que limitan la inserción laboral y la calidad del empleo de las mujeres: El caso chileno. Desarrollo y Sociedad, 77, 305-360. https://dx.doi.org/10.13043/dys.77.8

* Flego, Lucila, y Ortega, Julián. (2020). Mujeres en el trabajo: persistencia de los condicionantes de género en el ámbito laboral. CUHSO, 30(2), 160-188. https://dx.doi.org/10.7770/2452610x.2020.cuhso.05.a05

Freedman, J. (2004). Empleo y economía global. En Feminismos ¿Unidad o conflicto? (69-84). Narcea Ediciones. 
Garduño, E. (2021). La participación de las mujeres en STEM es baja: ¿Exclusión social o elección propia? Pacto de América Latina por la Educación con Calidad Humana. https://palech.org/la-participacion-de-las-mujeres-en-stem-es-baja-exclusion-social-oeleccion-propia/

Gómez, D; Huesca, L., y Horbat, J. (2017). Estudio de la segregación ocupacional por razón de género en el sector turístico de México. El Periplo Sustentable, 33, 159-191. https://rperiplo.uaemex.mx/article/view/4855

*González, F. y Arismendi, K. (2018). Student dropout in technical-professional higher education: Exploring factors that influence freshmen students. Revista de la Educación Superior, 47(188), 109-137. https://doi.org/10.36857/resu.2018.188.510

Grant, M. J. and Booth, A. (2009). "A typology of reviews: an analysis of 14 review types and associated methodologies". Health Information \& Libraries Journal, 26, 91-108. https://doi.org/10.1111/j.1471-1842.2009.00848.x

INE, Instituto Nacional de Estadísticas. (2021). Género y empleo: impacto de la crisis económica por covid-19. Boletín estadístico. Santiago de Chile. https://www.ine.cl/docs/defaultsource/genero/documentos-de-an\%C3\%A1lisis/documentos/g\%C3\%A9nero-y-empleoimpacto-de-la-crisis-econ\%C3\%B3mica-por-covid19.pdf

IST, Instituto Sindical de Trabajo, Ambiente y Salud y Mutual de seguridad. (2019). Mujer y vida laboral.

Jiménez, P., y Fernández, J. (2016). La brecha de género en la educación tecnológica. Ensaio, 24(92), 743-771. https://doi.org/10.1590/S0104-40362016000300 0010

Lexartza, Cabañas, Chávez y Fuentes. (2019). La brecha salarial entre hombres y mujeres en América Latina. En el camino hacia la igualdad salarial. OIT Américas. https://www.ilo.org/wcmsp5/groups/public/---americas/---ro-lima/documents/publication /wcms_697670.pdf

Liberati, A., Altman, D. G., Tetzlaff, J., Mulrow, C., Gøtzsche, P. C., loannidis, J. P., ... y Moher, D. (2009). The PRISMA statement for reporting systematic reviews and meta-analyses of studies that evaluate health care interventions: explanation and elaboration. Journal of clinical epidemiology, 62(10), e1-e34. https://doi.org/10.1016/j.jclinepi.2009.06.006

Maira, M. (2017). La segregación horizontal por género y sus consecuencias en la ocupación masculinizada de mecánico/a en el subsector de reparación de vehículos en España. Revista Laboreal, 13(1). https://doi.org/10.4000/laboreal.1796

Marchionni, M., Gasparini, L. y Edo, M. (2018). Brechas de género en América Latina. Un estado de situación. Banco de Desarrollo de América Latina.

Martin, A. (2008). Antropología del género. Culturas, mitos y estereotipos sexuales. Feminismos. Ediciones catedra. Universidad de Valencia, Instituto de la Mujer. https://fundacionjuntoscontigo.org/libros/29.pdf

Matus, C., Cornejo, M., y Castillo, F. (2020). The gender perspective in initial teacher training in Chilean Physical Education. Retos, 40, 326-335. https://doi.org/10.47197/RETOS .V1140.83082

*Maubrigades, S. (2020). Participation and gender occupational segregation in the economic sectors of Latin America during the 20th century. America Latina En La Historia Economica, 27(3). https://doi.org/10.18232/alhe.1046 
Melkas, H. y Anker, R. (1997). "La segregación profesional entre hombres y mujeres. Investigación empírica sobre los países nórdicos". Revista Internacional del Trabajo, 116(3), 371-394.

*Monteiro, S., Almeida, L., y Aracil, A. G. (2016). Graduates' perceptions of competencies and preparation for labour market transition: The effect of gender and work experience during higher education. Higher Education, Skills and Work-Based Learning, 6(2), 208-220. https://doi.org/10.1108/HESWBL-09-2015-0048

*Ng-Sueng LF, Vargas-Matos I, Mayta-Tristán P, Pereyra-Elías R, Montenegro-Idrogo JJ, IngaBerrospi F, et al. (2016) Gender Associated with the Intention to Choose a Medical Specialty in Medical Students: A Cross-Sectional Study in 11 Countries in Latin America. PLoS ONE, 11(8), e0161000. https://doi.org/10.1371/journal.pone.0161000

Nicolás, M; López, M; Cortés, R. (2008). La segregación ocupacional entre hombres y mujeres: teorías explicativas y análisis de su evolución reciente en España. http://proyectosocial.unizar.es/n13/N13_03.pdf

OIT. (1975). Declaración sobre la igualdad de oportunidades y de trato para las trabajadoras. Boletín Oficial. LVIII, Serie A (1). https://www.ilo.org/public/libdoc/ilo/P/09648/09648(1975A-1)104-109.pd\#page=3

ONU (2020). Objetivo 5: Lograr la igualdad entre los géneros y empoderar a todas las mujeres y las niñas. En Objetivos de desarrollo sostenible. https://www.un.org/sustainable development/es/gender-equality/

*Orellana, N. (2018). Consideraciones sobre empleabilidad en educación superior. Calidad en la Educación, 48, 273. https://doi.org/10.31619/caledu.n48.477

Recart, I; Valenzuela, J; Vaccarezza, G; Rodríguez, S; Contreras, M; Escare, K; Peñailillo, L y Cárdenas, C. (2020). "Documento de trabajo elaborado por equipo de proyecto "Desafío TEP".

*Sáez, M. (2019). La segregación de género en el mercado laboral: caso de los ingenieros comerciales de la Universidad de Chile [Tesis de maestría, Universidad de Chile]. https://repositorio.uchile.cl/handle/2250/175696

*Salce, F. (2021). Evolution and analysis of salary discrimination by gender in Chile. Trimestre Económico, 88(349), 39-75. https://doi.org/10.20430/ETE.V88I349.984

*Salinas, P. I., y Romaní, G. (2020). "Building bridges in higher education": A route between professional training and the mining industry of 2035. Cadernos Pagu,60, 1-33. https://doi.org/10.1590/18094449202000600013

*Salinas, P., y Romaní, G. (2017). Proyección laboral de las estudiantes mujeres en carreras mineras en la educación superior chilena. Formación Universitaria, 10(3), 31-48. https://doi.org/10.4067/S0718-50062017000300005

*Semenza, R., Boccardo, G., y Sarti, S. (2021). So Far, so Similar? Labour Market Feminization in Italy and Chile. Social Indicators Research, 154(3), 917-942. https://doi.org/10.1007/s11205-020-02551-0

*Sepúlveda, L. (2017). Aspiraciones y proyectos de futuro de jóvenes estudiantes secundarios en chile: el soporte familiar y su influencia en las decisiones educativo-laborales. Educação em Revista, 33(0). https://doi.org/10.1590/0102-4698158258

*Sepúlveda, L. (2019). Estudiantes mujeres en educación técnica profesional en Chile: continuidad y ruptura en inclusión educativa. Sintáctica, Revista Electrónica de Educación, 53, 1-19. https://doi.org/10.31391/s2007-7033(2019)0053-013 
*Sevilla, M. P., Sepúlveda, L., y Valdebenito, M. J. (2019). Gender differences production in Secondary Technical Vocational Education. Pensamiento Educativo, 56(1). https://doi.org/10.7764/PEL.56.1.2019.4

SiES. (2021). Brechas de género en educación superior 2020, 1-14. https://bibliotecadigital.mineduc.cl/bitstream/handle/20.500.12365/16821/Brechas $\% 20 \mathrm{Ge}$ nero\%20EdSup_2020.pdf?sequence=1\&isAllowed=y

Torns, T y Recio, C. (2012). Las desigualdades de género en el mercado de trabajo: entre la continuidad y la transformación. Revista de Economía Crítica, 14, 178-202. http://revistaeconomiacritica.org/sites/default/files/Semimonografico-4.-Torns-Recio.pdf

*Undurraga, R. y Becker, J. (2019). Mujeres trabajadoras jóvenes y pensiones en Chile. Psicoperspectivas. Individuo y Sociedad, 18(3). https://doi.org/ 10.5027/psicoperspectivas-vol18-issue3-fulltext-1658

*Undurraga, R., y Hornickel, N. L. (2020). Women's Work Trajectories and Workplace Violence: A Gender Issue. Psykhe, 29(2), 1-14. https://doi.org/10.7764/psykhe.29.2.1494

UNESCO (Organización de las Naciones Unidas para la Educación, la Ciencia y la Cultura). (2019), Descifrar el código: la educación de las niñas y las mujeres en ciencias, tecnología, ingeniería y matemáticas (STEM).

UNICEF. (2020). Proteger trayectorias educativas, caja de herramientas. https://www.unicef.org/colombia/informes/caja-de-herramientas

*Vives, A; Gray, N; González, F y Molina, A. (2018). Gender and Ageing at Work in Chile: Employment, Working Conditions, Work-Life Balance and Health of Men and Women in an Ageing Workforce, Annals of Work Exposures and Health, 62, 475489. https://doi.org/10.1093/annweh/wxy021 